\title{
Special Issue on Global Sourcing: IT Services, Knowledge and Social Capital
}

\author{
Ilan Oshri', Julia Kotlarsky ${ }^{2}$ \\ ${ }^{1}$ Rotterdam School of Management, The Netherlands \\ ${ }^{2}$ Warwick Business School, Warwick, UK
}

Journal of Information Technology (2008) 23, 1-2. doi:10.1057/palgrave.jit.2000129

B y 2008 the estimates for revenues from offshore outsourcing of information technologies (IT) are predicted to be in the range of \$US25 billion, and over the next 5 years a compound annual growth rate in this industry is expected to be about $20 \%$ (Willcocks and Lacity, 2006). Furthermore, by 2006 over 200 firms from the Forbes 2000 companies have offshored activities totaling about $\$ 9$ billion worth of IT and business process outsourcing activities. While the phenomenon of offshore outsourcing is certainly expanding, recent evidence suggests that a large number of offshore outsourcing relationships have failed to live up to their promise (e.g. Aron and Singh, 2005). The reasons for these failures are many, ranging from poor quality delivered by vendors to rising management costs that result in frustration and disappointment. Collaboration between remote sites and ability to share and transfer knowledge between dispersed teams have indeed been mentioned in past research (e.g. Kotlarsky and Oshri, 2005; Oshri et al., forthcoming;) as imperative to successful IT offshore outsourcing projects in addition to certain capabilities that vendors and clients should develop, governing structures that they should put in place, and the bonding activities they should promote and make time for (Kotlarsky et al., 2007; Oshri et al., 2007a, b).

These issues were at the heart of the Global Sourcing Workshop that was held in Val d'Isere (France) in March 2007. This annual gathering of academics and practitioners offers a stage to discuss cutting edge ideas concerning IT outsourcing and offshoring. In 2007 the workshop focused on services, knowledge and innovation in IT outsourcing and offshoring. From the 21 papers presented and discussed in the workshop, ${ }^{1}$ four were eventually selected for this special issue.

The first paper by Sirkka Jarvenpaa and Ji-Ye Mao examines the capabilities developed by Chinese vendors operating according to the mediated offshoring business model. The paper focuses on understanding the capabilities needed by such vendors to successfully deliver services. In particular, they examine the development of operational capabilities, which are those involved in the provision of a service or a product and that consist of three types: clientspecific capabilities, process capabilities, and human resources capabilities. Jarvenpaa and Mao conclude the paper, based on data collected in four Chinese firms, suggesting that human resources capabilities are the most important in this specific context.
The second paper by Volker Mahnke, Jonathan Wareham and Niels Bjorn-Andersen explores the role of the 'middleman' in offshore outsourcing. This paper argues that in recent years we have seen the emergence of a new breed of entities, which are offshore intermediaries. These entities specialize in bridging cultural, expertise and communication gaps between a vendor and a client. Through boundary spanning capabilities, the paper explores cultural, distance, pre- and post-contractual management aspects involved in intermediating trans-national offshoring relationships.

The third paper by Joseph Rottman focuses on knowledge transfer and social capital in offshore outsourcing relationships. The paper considers social capital as the vehicle through which value is created through social relationships. The paper argues that it is important who the supplier knows in the client organization and vice versa. Through these social relationships, knowledge can flow and value can be created for both client and vendor. A case from a Fortune 100 manufacturing firm illustrates the importance of social capital and the impact on both knowledge transfer and the management of global IT suppliers.

The fourth paper by Gary David, Donald Chand, Sue Newell and João Resende-Santos deals with the issue of collaboration between offshore and onsite teams. By applying World-Systems Theory, the authors claim that collaboration is understood as the relationships between remote sites, instead of the traditional approach in which the focus has been on a single site or a group of sites. This paper indeed highlights the role that socio-politico organizational context plays in creating relationships and generating tensions between sites. The paper concludes that tensions and breakdowns are also the result of how members of a globally distributed team perceive themselves, as core or periphery. Consequently, the key issue is power and not only culture or ICT.

The four papers in this special issue bring some key learning together. First, they show that offshore outsourcing should be treated as a context-dependent scenario. What is critical for the American middleman might not be imperative for the Chinese mediating firm. Secondly, this selection of articles brings together vendor/client capabilities with the broader picture of supply network and the rather micro-processes involved in managing knowledge transfer and globally distributed collaboration. These are indeed the building blocks of any global sourcing relationships. We hope this collection of articles is of value for research and practice. 
of knowledge management and work division, Journal of Information Technology 22(2): 161-173.

Oshri, I., Kotlarsky, J. and Willcocks, L.P. (2007a). Missing Links: Building critical social ties for global collaborative teamwork, Communications of the ACM 50(12): 63-67.

Oshri, I., Kotlarsky, J. and Willcocks, L.P. (2007b). Managing Dispersed Expertise in IT Offshore Outsourcing: Lessons from Tata Consultancy Services, MISQ Executive 6(2): 53-65.

Oshri, I., Van Fenema, P. and Kotlarsky, J. (2008). Knowledge Transfer in Globally Distributed Teams: The role of transactive memory, Information Systems Journal, forthcoming.

Willcocks, L. and Lacity, M. (2006). Global Sourcing of Business and IT Services, London: Palgrave.
Kotlarsky, J., Oshri, I., Kumar, K. and van Hillegersberg, J. (2007). Globally Distributed Component-Based Software Development: An exploratory study
Aron, R. and Singh, J. (2005). Getting Offshoring Right, Harvard Business Review 8(12): 135-143.

Kotlarsky, J. and Oshri, I. (2005). Social Ties, Knowledge Sharing and Successful Collaboration in Globally Distributed System Development 